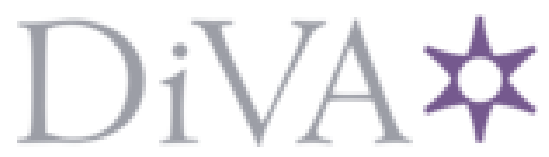

http://www.diva-portal.org

This is the published version of a paper published in Journal of Applied Sciences.

Citation for the original published paper (version of record):

Kormi-Nouri, R., Mahdavian, A. (2008)

Effects of attention and levels of processing on explicit and implicit memory function with interesting and unteresting tasks in university students.

Journal of Applied Sciences, 8(6): 1055-1060

Access to the published version may require subscription.

N.B. When citing this work, cite the original published paper.

Permanent link to this version:

http://urn.kb.se/resolve?urn=urn:nbn:se:oru:diva-35920 
Journal of Applied Sciences 8 (6): 1055-1060, 2008

ISSN 1812-5654

(C) 2008 Asian Network for Scientific Information

\title{
Effects of Attention and Levels of Processing on Explicit and Implicit Memory Function with Interesting and Uninteresting Tasks in University Students
}

\author{
${ }^{1}$ Alireza Mahdavian and ${ }^{2}$ Reza Kormi-Nouri \\ ${ }^{1}$ Department of Psychology, University of Science and Culture, Tehran, Islamic Republic of Iran \\ ${ }^{2}$ Department of Psychology, University of Tehran, Tehran, Islamic Republic of Iran
}

\begin{abstract}
This study aims to investigate the effect of attention and levels of processing on memory function and recalling words in two situations when students are interested in the subject and when they are not. This is an experimental study of 160 students conducted individually using a computer software. Results reveal focused attention, interest in the subject and deep processing caused the explicit memory to be at its highest level of functionality. On the contrary, shallow processing, divided attention and lack of interest in the subject plunged memory function into its lowest levels. Variables have different effects on attention, explicit and implicit memory. That is, interesting tasks with focused attention and deep processing have the highest effect on explicit memory in order. Also, interesting tasks, focused attention, respectively affect implicit memory. But level of processing does not affect implicit memory significantly.
\end{abstract}

$\underline{\text { Key words: Focused attention, divided attention, interest, explicit memory, implicit memory, University students }}$

\section{INTRODUCTION}

In recent decades, studies, researchers and education psychologists have revealed that education is more effective when instructors use more modern methods. In one of these studies, Craik and Lockhart (1996) proposed education based on levels of processing, in which perception of a stimulus occurs at different depths of processing. In the first step, the stimulant is perceived through its physical and emotional characteristics. In other steps, perception is conveyed at deeper levels. In other words, encoding depth theory is based on processing of levels instead of different memory systems. That is, in stage one, information is processed through its superficial and perceptive characteristics (shallow processing) and in stage two, through semantic and deeper characteristics (deep processing). Accordingly, keeping one item in memory depends on the depth of information processing.

Another important factor in learning is the attention of learners to the subject. Attention is a conspicuous and controversial topic for psychologists. It is every single student's wish -at least once- to learn all parts of a book at once or during sleep and not to forget it. There are even some advertisements in newspapers that claim learning during sleep. The fact is that no information can enter our mind or stay there without paying attention. Attention can be intentionally drawn to or away from a subject, but it is not that easy to have everything under control. Trying to keep our attention focused on a subject depends on many factors such as interest, motivation and attention exercise and attention management. The effects of lack of attention can be seen in our daily life, for instance, hearing someone's words, but not understanding what they say because our attention is somewhere else (Mangal, 2002).

Attention is divided into two categories: focused and divided. Focused attention can be studied by simultaneous presentation of two or more stimuli, one of which should be focused on. This way, we can realize how effectively people choose one stimulus and ignore others. Also studying divided attention reveals processing limits of human brain in paying attention to several stimuli (Eysenck and Keane, 2000).

In addition to attention and its depth, interest is another effective factor in learning. Interest, which entails pleasant emotional consequences, is usually related to non-competitive goals of earning process (Sansone and Smith, 2000; Chen and Ennis, 2004).

Krapp et al. (1992) quoted by Chen and Ennis (2004) discriminated individual and situational interest. Individual interest applies to psychological tendency of people to prefer an activity. Situational interest is defined as special attraction to an activity. Both kinds of interests interact, so they are considered as the combination of individual-situation; for example, interest in an activity, a

Corresponding Author: Alireza Mahdavian, Department of Psychology, University of Science and Culture, Tehran, Islamic Republic of Iran 
thing, an idea or an event. Interests contain special parts like cognitive and emotional ones (Chen and Ennis, 2004). Interest in a subject determines the way students as process the content of the lesson. It is clear that the process is different between the interesting subjects and uninteresting ones (Hidi, 1990).

Since both attention and interest are of special importance in learning process, the ability to concentrate on subjects to reach educational goals is essential. Traditionally, it is assumed that attention is necessary for recording information. In recent theories, it is claimed that focused attention improves information encoding in memory (Bentin, 1994; Cowan, 1988, 1995; Craik, 1989; Craik et al., 1996; Mulligan and Stone, 1999). On the other hand, divided attention at the time of encoding decreases explicit memory function (Baddeley et al., 1984; Broadbent, 1958; Cherry, 1953; Craik et al., 1996) quoted by Mulligan and Stone (1999).

Troyer and Craik (2000) studied the effect of divided attention on vocabulary memory. The results showed that divided attention, compared with focused attention, during encoding or restoring stage, reduces the subjects' function in all assignments. Likewise, Parkin and Russo (1990) and Szymanski and MacLeod (1996) concluded that manipulation of attention can affect explicit memory encoding, but has no effect on implicit memory tests. These researchers emphasize that divided attention or distraction hurts function of the subjects' explicit memory while implicit memory is not hurt quoted by MacDonald and MacLeod (1998). The effect of focused attention and divided attention on memory-especially implicit memory should be studied more. Some researchers believe that implicit memory is hurt less by divided attention due to its dependence on automatic encoding (Bentin, 1994; Parkin and Russo, 1990; Szymanski and MacLeod, 1996; Wolters and Prinsen, 1997) quoted by Mulligan and Stone (1999).

Parkin et al. (1990) proved that recognition with divided attention is far weaker than with focused attention. Meanwhile, there was no difference between divided and focused attention in Word-Completion Memory Test (WCMT). These results suggest that in spite of lack of attention at the time of studying words, implicit memory has worked well. Therefore, it seems the effect of divided attention on implicit memory is not the same as that on explicit memory.

In several studies, the role of levels of processing, attention and interest on memory function and learning separately has been studied and their positive effect has been proved. However, there has been no study on the combination of the three factors. This study aims at comparing the highest brain performance and memory at recalling interesting and uninteresting tasks.
The objectives of this study were to determine the effect of attention (divided and focused), level of processing (shallow and deep) and interest in subject (interest and disinterest) on recalling with lead (explicit memory evaluation) and completing words (implicit memory evaluation); to determine the effect of attention (focused and divided) on recalling with lead and completing words on the condition of shallow or deep processing and the condition of interest or disinterest; to determine the depth of processing effect (shallow or deep) on recalling with lead and completing words on the condition of interest or disinterest.

\section{MATERIALS AND METHODS}

From April to June of 2005 , this experimental study enrolled 160 BS Students from Engineering Faculty of Science and Culture University who were clusterrandomly selected. That is, out of 3 faculties of human sciences, art and engineering, the last one was randomly selected. Then students from departments of industry, computer and civil engineering were invited to participate in the study. Students were randomly assigned to one of the experimental groups.

A computer software was developed for the study. The following subjects were chosen: physics, chemistry, biology, math, philosophy and logic, geography, history, psychology, art and Persian literature. Next, any words related to each subject were selected in university exam booklet. Consulting with experts, we deleted irrelevant or interdisciplinary words. Two questions were made for each word; one whose answer was yes and another whose answer was no. On the whole, 44 words were selected, 24 of which were randomly shown to the subjects one after another. The software showed the words randomly and the recorded each subject's response and correct answers. At the time of recalling, two lists of the first three letters of words were given to subjects. Half of the words were the ones shown to subjects and half were the ones not shown to subjects. Also, the answer to half of the words was yes and to the other half was no. The words were shown in the same fashion in size, color, font and location for all subjects.

The test was given individually. Each student was given a number on entrance, which showed which case group they belonged to. The number of students in each group was 20 . The first group was the students who were interested in the selected subject. They answered the questions with focused attention. The questions were of the shallow encoding type. The second group was the students who were interested in the selected subject. They answered the question with divided attention. The 
questions were of the deep encoding type. The third group was the students who were disinterested in the selected subject. They answered the questions with focused attention. The questions were of shallow encoding type. The fourth group was the students who were disinterested in the subject. They answered the questions with focused attention. The questions were of the deep encoding type. Groups 5 to 8 had the same conditions as those of the first four groups except that they answered questions with divided attention (answering questions while doing another mental calculation like counting down). Immediately after the test, subjects were tested for IQ using the computer based Ryon adult IQ test. The IQ test was aimed at providing a suitable gap of $30 \mathrm{~min}$ to transfer data from short-term memory to long-term memory and also not to let the subjects review and process words more. Moreover, it helped us equalize the subjects for their intelligence.

After the Ryon test, the second part of the test (recalling) started. Two lists of the first three letters of 20 words were printed on A4 sheets and given to the subjects. Half of the words were seen by subjects before and the other half were not. Without knowing the relationship between these incomplete words with the words they had seen in the first part, subjects were asked to complete the word with the first word that came to their mind after they saw the first three letters (evaluating implicit memory). After the first paper was done, subjects were given another paper similar to the first one. Students were asked to complete the incomplete words on the second paper by recalling the words from the first paper (evaluating explicit memory). Each recalled word was given one score (both in the first and the second paper). The data were analyzed using variance analysis methods.

\section{RESULTS}

Evaluating explicit memory function (Table 1) revealed that the highest memory function belonged to group 2 and then came groups $6,1,5,4,8,3$ and 7 , respectively.

As shown in Table 2, the main effect of attention, processing and interest was significant on explicit memory. However, the interaction effects were not significant. The new finding is that we found the effect size using data in Table 2 and the formula,

$$
F=\frac{\sqrt{\left.\frac{p-1}{\text { mp }} M S B G-M S W G\right)}}{\text { MSWG }}
$$

(Kirk, 1995) ( $\mathrm{P}$ stands for the number of independent variable levels, $\mathrm{n}$ shows the number of subjects, MSWG stands for Mean Square Between Groups and MSWG stands for Mean Square Within Groups).

\begin{tabular}{llllll}
\multicolumn{6}{l}{ Table 1: Descriptive statistics of groups in explicit memory $(\mathrm{n}=160)$} \\
\hline Groups & Attention & Processing & Interest & $\mathrm{N}$ & Mean $\pm \mathrm{SD}$ \\
\hline 1 & Focused & Shallow & Interest & 20 & $7.10 \pm 2.13$ \\
2 & Focused & Deep & Interest & 20 & $7.75 \pm 1.16$ \\
3 & Focused & Shallow & Disinterest & 20 & $5.75 \pm 1.59$ \\
4 & Focused & Deep & Disinterest & 20 & $6.45 \pm 1.36$ \\
5 & Divided & Shallow & Interest & 20 & $6.50 \pm 1.40$ \\
6 & Divided & Deep & Interest & 20 & $7.15 \pm 1.60$ \\
7 & Divided & Shallow & Disinterest & 20 & $4.75 \pm 2.20$ \\
8 & Divided & Deep & Disinterest & 20 & $6.20 \pm 1.15$ \\
\hline
\end{tabular}

Table 2: Three way ANOVA in explicit memory for groups $(n=160)$

\begin{tabular}{|c|c|c|c|c|c|}
\hline Variables & Sum SQ & $\mathrm{df}$ & $\begin{array}{l}\text { Mean of } \\
\text { sum SQ }\end{array}$ & $\mathrm{F}$ & Sig. \\
\hline Attention (A) & 15.006 & 1 & 15.006 & 5.749 & $0.018^{*}$ \\
\hline Processing (B) & 29.756 & 1 & 29.756 & 11.400 & $0.001^{* * *}$ \\
\hline Interest (C) & 71.556 & 1 & 71.556 & 27.414 & $0.0001^{* * *}$ \\
\hline Interaction $\mathrm{A} * \mathrm{~B}$ & 1.406 & 1 & 1.406 & 0.539 & $0.464 \mathrm{NS}^{* * *}$ \\
\hline \multicolumn{6}{|l|}{ Non significance } \\
\hline Interaction $\mathrm{A}^{*} \mathrm{C}$ & $6.250 \mathrm{E}-03$ & 1 & $6.250 \mathrm{E}-03$ & 0.002 & $0.961 \mathrm{NS}$ \\
\hline Interaction $\mathrm{B}^{*} \mathrm{C}$ & 1.806 & 1 & 1.806 & 0.692 & $0.407 \mathrm{NS}$ \\
\hline Interaction $A^{*} \mathrm{~B}^{*} \mathrm{C}$ & 1.406 & 1 & 1.406 & 0.539 & $0.539 \mathrm{NS}$ \\
\hline $\begin{array}{l}\text { Between groups } \\
\text { variables }\end{array}$ & 396.750 & 152 & 2.610 & & \\
\hline Sum & 571.694 & 160 & & & \\
\hline
\end{tabular}

${ }^{*} \mathrm{p}<0.05, * * \mathrm{p}<0.01, \mathrm{NS}$ : Non significant

Table 3: Descriptive statistics of groups in implicit memory $(n=160)$

\begin{tabular}{llllll}
\hline Groups & Attention & Processing & Interest & $\mathrm{N}$ & Mean \pm SD \\
\hline 1 & Focused & Shallow & Interest & 20 & $6.20 \pm 2.89$ \\
2 & Focused & Deep & Interest & 20 & $7.25 \pm 2.34$ \\
3 & Focused & Shallow & Disinterest & 20 & $5.25 \pm 2.34$ \\
4 & Focused & Deep & Disinterest & 20 & $4.50 \pm 1.91$ \\
5 & Divided & Shallow & Interest & 20 & $4.70 \pm 1.84$ \\
6 & Divided & Deep & Interest & 20 & $5.80 \pm 2.35$ \\
7 & Divided & Shallow & Disinterest & 20 & $4.30 \pm 2.03$ \\
8 & Divided & Deep & Disinterest & 20 & $4.20 \pm 1.82$ \\
\hline
\end{tabular}

The results showed that effect size of attention, processing and interest was $0.35,0.51$ and 0.81 , respectively; therefore, the highest change in explicit memory function was associated with interest, then with levels of processing and finally with attention.

Table 3 shows our findings about implicit memory function. Group 2 showed the highest function and groups $1,6,3,5,4,7$ and 8 followed in order. Summary of variance analysis can be shown in Table 4 .

The main effect of attention and interest was significant on implicit memory. Among interaction effects, only interaction effects of processing with that of attention was significant. A new finding is that effect size of attention is 0.45 and that of interest is 0.63 , which means most of the change in implicit memory function depends on interest and then attention. Furthermore, levels of processing don't have a significant effect on implicit memory function.

To clarify the differences and similarities between implicit and explicit memory, recalling words in different conditions is shown in Fig. 1. In all groups, explicit memory function was higher than implicit memory 
Table 4: Three way ANOVA in implicit memory for groups $(n=160)$

\begin{tabular}{|c|c|c|c|c|c|}
\hline Variables & Sum SQ & $\mathrm{df}$ & $\begin{array}{l}\text { Mean of } \\
\text { sum SQ }\end{array}$ & $\mathrm{F}$ & Sig. \\
\hline Attention (A) & 44.100 & 1 & 44.100 & 9.077 & $0.003^{\text {**** }}$ \\
\hline Processing (B) & 4.225 & 1 & 4.225 & 0.870 & $0.353 \mathrm{NS}$ \\
\hline Interest (C) & 81.225 & 1 & 81.225 & 16.718 & $0.0001^{* * *}$ \\
\hline Interaction $\mathrm{A} * \mathrm{~B}$ & 1.225 & 1 & 1.225 & 0.252 & $0.616 \mathrm{NS}^{* * * *}$ \\
\hline \multicolumn{6}{|l|}{ Non significance } \\
\hline Interaction $A^{*} \mathrm{C}$ & 7.225 & 1 & 7.225 & 1.487 & $0.225 \mathrm{NS}$ \\
\hline Interaction $\mathrm{B}^{*} \mathrm{C}$ & 22.500 & 1 & 22.500 & 4.631 & $0.033^{*}$ \\
\hline Interaction $A^{*} B^{*} C$ & 0.900 & 1 & 0.900 & 0.185 & 0.668 \\
\hline $\begin{array}{l}\text { Between groups } \\
\text { variables }\end{array}$ & 738.500 & 152 & 4.859 & & \\
\hline Sum & 5352 & 160 & & & \\
\hline
\end{tabular}

${ }^{*} \mathrm{p}<0.05, * * \mathrm{p}<0.01$

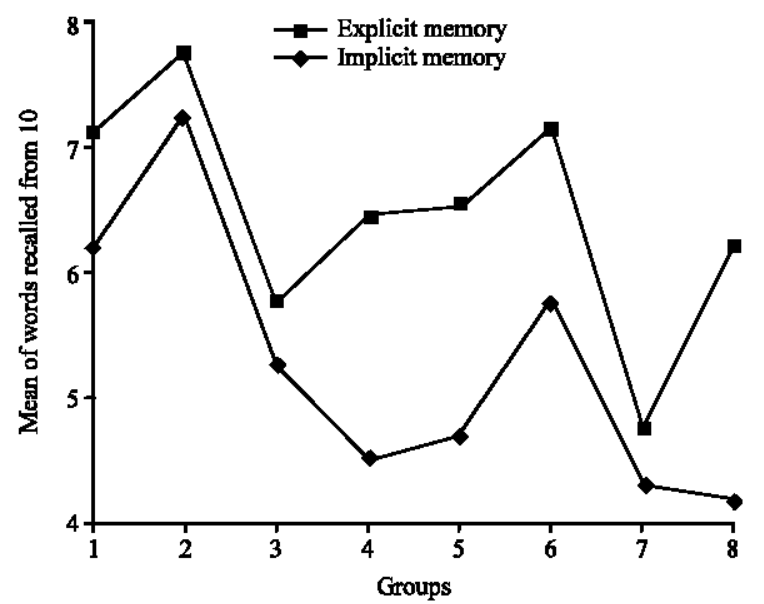

Fig. 1: Comparison of explicit memory function and implicit memory function

function and it increased or decreased in one direction in groups $1,2,3,6$ and 7 . However, no significant difference was found between the two in groups 4,5 and 8 .

\section{DISCUSSION}

The question is why deep processing, focused attention and interest can increase function of implicit and explicit memory to the highest level and in other groups, the function of both memories remain between these limits after changes are made to attention, interest and processing. This finding can be approached in two ways. From theoretical point of view, the most important goal of this research was to study the combination of the three factors of attention, interest and levels of processing. The results of this study clearly answer this question. With deep processing, focused attention and interest, the highest memory function can be reached. In groups which one or more of the factors were replaced with divided attention, shallow processing and disinterest, memory function decreases gradually. In groups 7 and 8, which all decreasing factors were combined, memory function reached its lowest level. Theoretically, these findings are in line with the most important goals of the study. This shows consistency in mental processes including explicit memory.

From practical point of view, instructors should base their teaching methodology on full attention of learners; secondly, cognitive involvement of students with the subject and persuading them to use deeper processing (even though it is time-consuming) and thirdly, choosing subjects based on students interests. Therefore, the findings of this research in respect with focused attention effect on improvement of data encoding is in agreement with those of the following researches: Bentin (1994), Cowan $(1988,1995)$ and Craik (1989). Furthermore, other researches have shown that divided attention at the time of encoding decreases explicit memory function (Baddeley et al., 1984; Broadbent, 1958; Cherry, 1953; Craik et al., 1996; Fisk and Shneider, 1984; Mulligan, 1998; Murdock, 1965; Norman, 1969) quoted by Mulligan and Stone (1999).

Decreased attention and mental engagement with other things negatively affect memory, especially explicit memory. In fact, brain's processing capacity decreases with decreasing attention or increasing difficulty of doing two tasks simultaneously. For instance, in another research, memory function of attendees for encoding words along with a difficult task was worse than that of those who did it with an easier task (Baddeley et al., 1984; Craik et al., 1996). Both tasks were done at the time of divided attention, but when the second task was hard, memory function decreased more, which means data processing capacity of brain is limited. Thus, data processing capacity of brain is limited. Thus, data processing capacity in human has a consistent nature and is the most efficient with focused attention. As attention decreases (divided attention), efficiency and function of cognitive processes (like attention) decrease. In addition to attention, depth of processing and interest act mostly in the same way. The effect of processing (deep or shallow) on explicit memory is not the same. In other words, rate of recalling words is much higher with deep processing. However, the results with implicit memory is different when the subject is of interest to learners, but when the subject is not interesting, deep processing decreases implicit memory function. This finding of the research is new and noticeable. This way, we can refer to researches that found the same results. However, they generally found that implicit memory is not affected by deep processing. For instance, in a study, it was found that at the time of learning, the deeper the processing, the better the memory function and recalling. This effect is seen in explicit memory, not in implicit memory. That is, 
processing, deep or shallow, does not affect implicit memory. Examining explicit memory reveals that recognition is affected by the depth of processing in that deep encoding results in the highest recognition. Meanwhile, Perceptual priming, which shows implicit memory, is not affected by the depth of processing.

Graf and Mandler (1984) quoted by Szymanski and MacLeod (1996) found out that the deeper the processing, the better the function of explicit memory. Implicit memory does not improve the same way, though. Implicit memory function in other groups falls between these two groups when attention, interest and processing are changed. The reason why implicit memory function is lower than that of explicit memory is that shallow processing and decreased attention can decrease the function of both memories.

According to Bentin et al. (1998), the following principles are proposed: (1) At the time of encoding, some attention (up to threshold) is necessary to affect function of implicit and explicit memory. (2) Even when a stimulus is attended to, there should be a little deep processing in order to affect implicit memory. (3) In vocabulary tests, the increase in threshold has a little effect on memory function and (4) In order to consciously recall at memory tests, there should be a higher threshold of attention and processing. As attention and processing surpass the threshold, memory function improves. Therefore, implicit memory function is always lower than that of explicit memory because implicit memory function is at the threshold. Explicit memory needs levels of processing higher than threshold. Although changes in explicit and implicit memory happen in parallel in groups $1,2,3,5,6$ and 7 , these changes occur in opposite direction in groups 4 and 8 . The reason for the difference can be explained using the result of the following studies: Jakobi and Dalas (1981) quoted by Medin et al. (2001). They found that at the time of learning, the deeper the data processing, the better the memory function and recalling [of explicit memory]. In other words, this effect is seen in explicit memory, not in implicit memory. That is, whether processing is deep or shallow, implicit memory function does not change.

Interest and disinterest do not have the same effect on function of explicit and implicit memory. In other words, you can recall more words when you are interested in the subject.

Other studies show the effect of interest, attention and processing on function of explicit and implicit memory. For example, Harris and Pashler (2004) showed the first and last letter of the words to the subjects and asked them to guess the letters between them. When the name of the subjects was called, the rate of their response was significantly lower. This delay was also observed when words had emotional load. In other words, a person's name or an emotional stimulus inadvertently draws the person's attention and take more time. Thus, emotional words affect attention and memory.

In this study, the importance of interest and its role in explicit memory can be realized from effect size. That is, in explicit memory, interest, processing and attention positively affect word recalling; therefore, interest is more important than attention and processing when it comes to learning and memorizing.

However, results are a little different for implicit memory. It means the order in which interest, attention and processing affect implicit memory is different. Interest and attention affect implicit memory in a positive and significant way, but levels of processing do not affect it. The reason for this has been stated before. The important point is that both for implicit and explicit memory, interest have the highest effect. In other words, even at the time of focused attention, if the subject is not interesting, there will be less effect on memory (explicit and implicit) compared with an interesting subject. This proves the effect and importance of emotions on cognitive issues.

There is a lot of evidence in different researches to prove the effect of interest in learning. Our findings are in line with those of other researches. Interest motivates students to try hard to understand a subject (Dewey, 1913) quoted by Chen and Ennis (2004). Hidi (1990) also proves that interest determines how students analyze or encode what they learn. The processing of an interesting subject is clearly different from that of uninteresting ones. Therefore, interest plays an unquestionable role in explicit and implicit memory.

In conclusion, we believe lessons should be selected in a way that accords with the interest of students.

\section{REFERENCES}

Baddeley, A., V. Lewis, M. Eldridge and N. Thomson, 1984. Attention and retrieval from long-term memory. J. Exp. Psychol. Gen., 113: 518-540.

Bentin, S., 1994. Semantic Processing of Ignored Stimuli: the Role of Attention in Memory. In: Attention and Performance Cambridge, MA, Umilta, C. and M. Moscovitch (Eds.). MIT Press, pp: 551-569.

Bentin, S., M. Moscovitch and O. Nirhood, 1998. Levels of processing and selective attention effects in encoding in memory. Acta Psychol., 98: 311-341.

Broadbent, D.E., 1958. Perception and Communication. Pergamon. London.

Chen, A. and C.D. Ennis, 2004. Goal, interests and learning in physical education. J. Educ. Res., 97: $329-338$. 
Cherry, E.C., 1953. Some experiments on the recognition of speech with one and with two ears. J. Acoustical Soc. Am., 26: 554-559.

Cowan, N., 1988. Evolving conceptions of memory storage, selective attention and their mutual constraints within the human information-processing system. Psychol. Bull., 104: 163-191.

Cowan, N., 1995. Attention and Memory: An Integrated Framework. Oxford University Press, New York.

Craik, F.I.M., 1989. On the Making of Episodes. In: Varieties of Memory and Consciousness: Essays in Honour of Endel Tulving, Roediger, H.L. and F.I.M. Craik (Eds.). Hillside, NJ: Erlbaum, pp: 43-57.

Craik, F.I.M., R. Govoni, M. Naveh-Benjamin and N.D. Anderson, 1996. The effects of divided attention on encoding and retrieval processes in human memory. J. Exp. Psychol. Gen., 125: 159-180.

Craik, F.I.M. and R.S. Lockhart, 1996. Levels of processing: A framework for memory research. J. Verbal Learn. Verbal Behav., 11: 671-684.

Dewey, J., 1913. Interest and Effort in Education. Boston: Riverside Press.

Eysenck, M.W. and M.T. Keane, 2000. Cognitive Psychology: A Student's Handbook. 4th Edn. Psychology Press Ltd., New York.

Fisk, A.D. and W. Schneider, 1984. Memory as a function of attention, level of processing and automatization. J. Exp. Psychol. Learn. Memory Cognition, 10: 181-197.

Graf, P. and G. Mandler, 1984. Activation makes words more accessible, but not necessarily more retrievable. J. Verbal Behav., 23: 553-568.

Harris, C.R. and H. Pashler, 2004. Attention and the processing of emotional words and names not so special after all. Psychol. Sci., 15 (3): 171-178.

Hidi, S., 1990. Interest and it's contribution as a mental resources for learning. Rev. Educ. Res., 60: 549-571.

Jakobi, L.L. and Dalas, 1981. Under relationship between auto biographical memory and perceptual learning. J. Exp. Psychol. Gen., 110: 306-340.

Kirk, R.E., 1995. Experimental Design: Procedures for the Behavioral Sciences. 3rd Edn. Brooks/Cole Publishing Company.

Krapp, A., S. Hidi and K.A. Renninger, 1992. Interest, Learning and Development. In: The Role of Interest in Learning and Development, Renninger, K.A., S. Hidi and A. Krapp (Eds.). Hillsdale, NJ: LEA., pp: 1-26.
MacDonald, P.A. and C.M. MacLeod, 1998. The influence of attention at encoding on direct and indirect remembering. Acta Psychol., 98 (2-3): 291-310.

Mangal, S.K., 2002. Advanced Educational Psychology. 2nd Edn. Prentice Hall of India Private Limited, New Delhi.

Medin, D.L., B.H. Ross and A.B. Markman, 2001. Cognitive Psychology. Harcourt Collage Publishers.

Mulligan, N.W., 1998. The role of attention during encoding on implicit and explicit memory. J. Exp. Psychol. Learn. Memory Cognition, 24: 27-47.

Mulligan, N.W. and M. Stone, 1999. Attention and conceptual priming: Limits on the effects of divided attention in the category-exemplar production task. J. Memory Language, $41: 253-280$.

Murdock, B.B., 1965. Effects of subsidiary task on short term memory. Br. J. Psychol., 56: 413-419.

Norman, D.A., 1969. Memory while shadowing. Q. J. Exp. Psychol., 21: 85-93.

Parkin, A.J. and R. Russo, 1990. Implicit and explicit memory and the automatic-effortful distinction. Eur. J. Cognitive Psychol., 2: 71-80.

Parkin, A.J., T.K. Reid and R. Russo, 1990. On the differential nature of implicit and explicit memory. Memory Cognition, 18: 507-514.

Sansone, C. and J.L. Smith, 2000. Interest and SelfRegulation: The relation Between having to and Wanting To. In: Intrinsic and Extrinsic Motivation: The Search for Optimal Motivation and Performance, Sansone, C. and J.M. Harackiewicz (Eds.). San Diego, CA: Academic Press, pp: 343-374.

Szymanski, K.F. and C.M. MacLeod, 1996. Manipulation of attention at study affects an explicit but not an implicit test of memory. Consciousness Cognition, 5: 165-175.

Troyer, K. and F.I.M. Craik, 2000. The effect of divided attention on memory for items and their context. Can. J. Exp. Psychol., 53: 161-171.

Wolters, G. and A. Prinsen, 1997. Full versus divided attention and implicit memory performance. Memory Cognition, 25: 764-771. 